\title{
Meio ambiente e desenvolvimento: construindo um novo campo do saber a partir da perspectiva interdisciplinar
}

\section{The environment and development: building a new field of knowledge based on the interdisciplinary perspective}

\author{
Claude RAYNAUT*
}

\begin{abstract}
RESUMO
O presente momento da sociedade é marcado por uma considerável crise do pensamento e de produção do conhecimento científico. Essa crise decorre também da divisão disciplinar do conhecimento, sendo que a interdisciplinaridade se apresenta como uma possibilidade de sua superação. Na perspectiva interdisciplinar os objetos e assuntos são híbridos e, em geral, reconhecidos a partir duma posição social que obriga a considerar a realidade tal como se apresenta na experiência comum abrangendo, portanto, uma consideração para além da condição científica disciplinar, constituindo problemáticas. A abordagem do meio ambiente e desenvolvimento encontra campo fértil nessa perspectiva, todavia esta constitui uma prática em construção. A noção de desenvolvimento sustentável sempre aparece associada a esta discussão, embora ainda revestida de expressiva ambigüidade.

Palavras-chave: meio ambiente, desenvolvimento, interdisciplinaridade, desenvolvimento sustentável.
\end{abstract}

\begin{abstract}
At present, society is marked by a considerable crisis in the thinking and production of scientific knowledge. This crisis results from the breaking down of knowledge into disciplines, while interdisciplinarity stands as a possibility for overcoming it. Under the interdisciplinary perspective, objects and subject-matters are hybrid and - by and large, acknowledged from a social standpoint that forces one to consider reality as it presents itself in common experience and thus encompassing a consideration that goes beyond the disciplinary scientific condition - become discussion issues. The environment and development approach finds fertile ground in this perspective, even though the latter is still praxis under construction. The notion of sustainable development always appears in association with this discussion, even if involved in expressive ambiguity.

Key-words: environment, development, interdisciplinarity, sustainable development.
\end{abstract}

\footnotetext{
* Doutor em Antropologia. Doutor Honoris Causa da UFPR. Professor da Universidade de Bordeaux II e Pesquisador do Centre National de la Recherche Scientifique, França. Professor convidado do Doutorado em Meio Ambiente e Desenvolvimento da UFPR.
} 
RAYNAUT, C. Meio Ambiente e Desenvolvimento: construindo um novo campo...

A comunidade científica e acadêmica passa hoje, em uma escala mundial, por um profundo movimento de interrogação sobre as modalidades de produção do saber. Tanto do lado das ciências "duras" como das ciências sociais, questionamentos surgem sobre a definição do objeto científico, sobre a condição do observador, sobre a pertinência de um esforço para achar regularidades e limites claramente estabelecidos dentro de um universo complexo submetido à desordem e imprevisibilidade.

Estamos em um momento crítico do desenvolvimento do pensamento humano. Ao mesmo tempo assistimos ao triunfo da ciência como instrumento de mudança de nossa existência individual e coletiva e ao questionamento do papel da mesma, junto com dúvidas sobre a natureza do conhecimento que ela traz. Muitas certezas estabelecidas sobre a herança do positivismo científico e da utopia do progresso e da modernidade vacilam.

\section{A crise contemporânea do pensamento}

Talvez se possa dizer que estamos passando por um movimento de revolução intelectual e moral equivalente àquele produzido durante a Renascença, quando os paradigmas que ordenavam a visão do universo e a percepção da posição do ser humano foram modificados ao mesmo tempo pelas descobertas galileana e coperniciana da não-centralidade da Terra no universo e pelo descobrimento do Novo Mundo. De repente, as definições e fronteiras bem estabelecidas, sobre as quais a representação do mundo havia sido construída durante séculos, foram desfeitas. De um mundo homogêneo e a-histórico, unificado no tempo e no espaço como reflexo da vontade de Deus, a representação passou a ser aquela de um mundo multi-cêntrico, redescobrindo-se sua dimensão histórica por meio da filiação reivindicada com as civilizações antigas.

Dentro dessa nova representação do universo, o ser humano achou um novo lugar e um novo papel, destacando-se do resto da criação, objetivando a realidade e colocando-se como sujeito e ator da sua existência. Foi um período de intensa renegociação dos paradigmas, das categorias do pensamento e dos valores morais, em função dos novos espaços de atuação assim abertos. Os desdobramentos dessa mudança de postura foram radicais, tanto no domínio da religião (com a Reforma), da filosofia e da ética (com o humanismo e a emergência do sujeito), da arte (com a fascinação pela herança do Mundo Antigo, a invenção da perspectiva plana, a redescoberta do indivíduo como modelo para a pintura ou a escultura), da ciência (com a sistematização da observação e da descrição dos objetos presentes na natureza: plantas, animais, astros). Foi um fantástico período de crise - no sentido etimológico que se refere ao momento em que rupturas críticas têm de ser decididas - com as suas muitas esperanças e possibilidades novas, mas também dúvidas, confrontos ideológicos, conflitos violentos e sangrentos.

É sempre muito arriscado fazer analogias e transposições entre períodos históricos. A história nunca se repete. Mas, às vezes, apresentam-se semelhanças que podem ajudar a entender melhor a realidade contemporânea. Acho pessoalmente que nós estamos entrando, mais uma vez, em um período histórico no qual estão sendo renegociados os recortes, definições e fronteiras que ordenam de maneira fundamental nossa percepção do mundo. Com os avanços das ciências e das técnicas, as fronteiras e as oposições que delimitavam de modo bastante nítido a posição do ser humano no mundo material e a relação das sociedades com sua própria materialidade (o corpo dos seus membros assim como seu ambiente) ficam cada vez mais frouxas.

Tanto no início da vida do ser humano (tratando-se por exemplo da qualificação do embrião) como no seu fim (tratando-se da definição da morte), são as representações da pessoa humana, do sujeito humano, que estão sendo submetidas a um processo de reelaboração. Com as perspectivas abertas pelas biotecnologias e, mais recentemente, pelas técnicas de clonagem, o ser vivo - planta, animal, e talvez no futuro próximo o próprio ser humano - tornamse artefatos, produtos da atividade humana, o que quer dizer coisas e, conseqüentemente, mercadorias atuais ou potenciais. Poderíamos tomar outros exemplos, na escala macro, no tocante às conseqüências conceituais da exploração do universo, à descoberta do planeta Terra como universo finito que não fica de fora do alcance das intervenções humanas.

Enfim, com o desenvolvimento das ciências humanas e sociais, o indivíduo e a sociedade tornaram-se objetos de conhecimento. Os debates e as interrogações sobre as instituições e as práticas deixaram progressivamente de examinar sua conformidade a regras e princípios morais ou religiosos preestabelecidos ou transcendentes. O esforço deslocou-se no sentido de identificar as "leis" psicológicas, sociológicas e econômicas que governam a vida dos sistemas sociais e cujo conhecimento poderia permitir controlá-los e orientá-los em função de um projeto. "Con- 
siderar os fatos sociais como coisas" foi um dos preceitos fundamentais de Emile Durkheim, fundador da sociologia. À medida que o ator social desenvolve sua capacidade de distanciar-se mentalmente em relação à sua própria sociedade, de criticar suas regras e instituições, abre-se para ele a esperança de poder manejá-la como se maneja um sistema físico ou natural. De uma certa maneira, a sociedade humana, submetida ao olhar das ciências sociais, entra em um processo de objetivação e, desse modo, reintegra o resto do mundo.

À medida que evoluíam o conhecimento, as representações mentais e os instrumentos de ação sobre o mundo em todos os seus componentes (humanos, físicos, naturais), esmaeceu a dicotomia entre o ser humano e os outros seres vivos ou inertes no mundo. No olhar da ciência, mas também na busca de soluções práticas para resolver os problemas individuais e coletivos, observou-se uma dupla mudança:

- o ser humano começa a perder seu estatuto de "extraterritorialidade" ontológica. Como ser vivo, ele não se destaca radicalmente dos outros seres e das outras coisas que, ao seu lado, compõem a totalidade do mundo, todos compartilhando a mesma genealogia. O corpo humano torna-se matéria física, matéria viva como qualquer outra. Os sistemas sociais e econômicos, por complexos que sejam, são analisados nas suas estruturas, suas regularidades, das quais se busca inferir regras de funcionamento que permitam manejálos e manipulá-los como qualquer outro sistema;

- o mundo material, no que lhe diz respeito, tanto nas suas escalas mais infinitesimais quanto nas mais amplas, não se apresenta mais como um "dado" intangível no qual o Homem deve se adaptar. Ele é doravante - para o melhor ou o pior aberto à intervenção demiúrgica dos seres humanos, diretamente ou indiretamente exposto à realização das suas aspirações e dos seus fantasmas.

Simplificando para enfatizar as grandes tendências, poder-se-ia dizer que assistimos a um processo simétrico de "naturalização" do ser humano e de "antropização" do mundo material. Não é este o lugar para analisar e discutir de maneira aprofundada a genealogia do pensamento moderno - nas suas ligações tão fortes com a cultura ocidental - mas talvez seja pertinente apontar uma contradição desse pensamento entre a afirmação "humanista" que destaca o ser humano como ponto central da criação e o enfoque homogeneizador do olhar científico que considera, sem diferenciação, todos os componentes do mundo como objetos potencialmente submetidos a um mesmo processo epistemológico de objetivação e de construção do conhecimento. Essa contradição latente atinge hoje seu ponto mais agudo e está impondo mutações radicais nos paradigmas que fundamentam nossa representação conjunta do mundo e do homem.

Hoje em dia, estão acontecendo ieráveis discussões éticas relativas à regulação das práticas médicas, das biotecnologias, das manipulações genéticas ou do uso da tecnologia. Especialistas conduzem debates jurídicos sobre a valorização econômica dos elementos naturais e sobre a possibilidade de patentear o vivente. Muitas discussões surgem sobre a difícil conciliação entre os objetivos do desenvolvimento humano e a proteção do ambiente. Todas essas discussões, debates e confrontos de opiniões, uma vez que deixam de suscitar princípios definidos, de início, como universais e intangíveis, não passam de difíceis esforços de renegociação de sentido no tocante ao estatuto, à posição e às relações mútuas do homem e do mundo material (inclusive o próprio corpo humano).

De maneira muito simplificada, a questão fundamental seria: como pensar e definir a singularidade respectiva do ser Humano e do mundo material, sem manter uma dicotomia e aceitando a idéia de uma continuidade entre um e o outro?

\section{O papel da ciência na resolução da crise cultural}

A ciência desempenhou um papel fundamental na emergência da crise que acabamos de resumir. Ela afirma que, ao utilizar os seus próprios critérios de descrição da realidade, uma separação radical entre o homem e o resto do universo não tem fundamentos. Ao mesmo tempo, ela não afirma que tudo seja igual. Ainda que o homem compartilhe muita coisa com os outros seres vivos ou inertes, todos possuindo a mesma genealogia, destaca-se por ser capaz de tomar a distância da consciência e de pensar em si mesmo e no todo em seu entorno. Pode-se dizer que a consciência e a capacidade de formar idéias e de criar sentido são características específicas da espécie humana, mesmo que a paleontologia mostre que elas emergiram no decorrer de um lento processo evolutivo e que os estudos 
RAYNAUT, C. Meio Ambiente e Desenvolvimento: construindo um novo campo...

etológicos sugiram, hoje, ainda que neste domínio, os limites entre o ser humano e os animais não são sempre tão estanques como se tinha pensado.

Essas especificidades, por essenciais que sejam para definir a singularidade do ser humano, não caem fora da perspectiva "objetivante" da ciência: a consciência e os processos ideacionais são objetos de estudo para a neurologia e para as ciências cognitivas. Portanto, até na sua dimensão de ser pensante, o ser humano fica submetido ao esforço explicativo da ciência. Na qualidade de objeto de estudo, ele se junta a todos os outros objetos potenciais da ciência.

Apesar da unicidade do mundo sob o olhar da ciência e muito embora o ser humano esteja profundamente encaixado no resto do mundo - é um animal com características particulares, mas não deixa de ser um animal! - o exercício da sua consciência, da sua capacidade cognitiva e do movimento dos seus sentimentos conduz à produção de fatos imateriais que desfrutam de uma existência autônoma em relação à dimensão física do mundo. Representações, símbolos, saberes, saber fazer, fantasmas, emoções processos conscientes e não-conscientes - interagem entre si, se influenciam, se acumulam ou se destroem, criando uma história que nunca pode ser totalmente reduzida às determinações do contexto físico ou biológico. As idéias, por si mesmas, geram novas idéias; ideologias eliminam outras ideologias, descobertas permitem novas descobertas, criações artísticas constituem o alicerce sobre o qual vão se edificando outras formas de criação. Ao mesmo tempo, lutas de poder inspiradas por aspirações, busca de identidade, fanatismo religioso são evidenciados como forças pujantes da história humana. Muito mais sangue humano foi derramado, mais danos ambientais causados - mas também muito mais progressos foram conseguidos - em nome de ideologias, de utopias, de princípios morais, religiosos ou políticos do que na busca da satisfação de necessidades físicas.

Os indivíduos e as sociedades humanas, por terem uma consciência e por serem produtores de sentido, têm a capacidade de se afirmarem como sujeitos da sua história, de criar, em relação ao mundo, a distância que lhes permite encará-lo "de fora", apesar de serem parte constitutiva deste mesmo mundo. O pensamento científico é a manifestação mais evidente dessa dupla postura. A ciência pode descrever a realidade que observa, valendo-se dos instrumentos conceituais e metodológicos que possui em um certo momento de sua história. Pode analisar e às vezes tentar prever as conseqüências das ações humanas. Mas não tem condições para decidir o valor, o sentido que o ser humano deveria atribuir a si mesmo, às suas relações com seus congêneres e às suas relações com o resto do mundo. Onde colocar as fronteiras no âmbito do espaço de novas possibilidades abertas pela ciência e pelas técnicas? Como qualificá-las em função das categorias do Bem e do Mal, do Justo e do Injusto, do que se pode aceitar e do que se deve rejeitar? É somente em si mesmos, apoiando-se no sentido que querem dar à sua existência, que os seres humanos vão achar - individualmente e coletivamente - os critérios para decidir. A ciência pode ajudar a clarificar as conseqüências das várias escolhas possíveis. Ela não pode fornecer os critérios últimos de decisão. A Ciência não fundamenta a Ética.

No entanto, frente a esses novos desafios, ela tem responsabilidades e papéis essenciais. Em particular, evidenciar o caráter não intrínseco das categorias, das fronteiras e dos recortes aplicados quando se pensa o mundo, quando se define a posição que o ser humano ocupa nele; permitir ir além das simplificações e melhor entender a complexidade do mundo. Tal objetivo chama por novas formas de construção do conhecimento.

A questão da legitimidade do recorte disciplinar ocupa uma posição central nessas interrogações e o apelo para a interdisciplinaridade se expressa de modo recorrente. Não se encontra uma definição da interdisciplinaridade que seja consensual e menos ainda uma doutrina estabelecida que possa ser aplicada ao trabalho de campo. Torna-se, então, imprescindível definir com clareza as bases teóricas e metodológicas em torno das quais se constrói um projeto de prática concreta da interdisciplinaridade. Vou me apoiar aqui na experiência conduzida durante 10 anos no quadro do Doutorado em Meio Ambiente e Desenvolvimento da Universidade Federal do Paraná e recapitular os pontos mais relevantes da postura intelectual adotada.

\section{Interdisciplinaridade não significa acabar com as disciplinas}

O desafio fundamental ao se adotar um enfoque interdisciplinar é tentar restituir, ainda que de maneira parcial, o caráter de totalidade e de complexidade do mundo real dentro do qual e sobre o qual todos pretendemos atuar. Como acabamos de dizer, se muitas fronteiras e limites são hoje questionados, é justamente por não serem intrínsecos 
à realidade do mundo e se revelarem, cada vez mais, ligados a representações construídas dessa realidade.

"Totalidade" e "complexidade" são palavras que surgem todas as vezes em que se fala de interdisciplinaridade. O mundo real, na sua essência, é total. Ele é feito de interações múltiplas e complexas entre os muitos elementos que o compõem, não conhecendo ou admitindo fronteiras estanques. Essa totalidade do mundo, sua unicidade, as correspondências entre os elementos que o compõem constituíram um dos primeiros modos de construção da consciência do universo pelo pensamento humano e da concepção da posição do homem nele. Muitas foram e são as maneiras de afirmar e tentar apreender essa unicidade. É o caso do pensamento mítico, de várias correntes filosóficas e das religiões que submetem toda a Criação à vontade unificadora de um Deus único.

A novidade trazida pelo pensamento científico, quando comparado a outras formas de pensamento, foi justamente a de aceitar a dividir o mundo em facetas ou níveis de organização diferentes e tentar desenvolver instrumentos específicos - conceitos, definições de objetos, métodos de observação - para tentar explicar os fenômenos observados dentro dos limites assim delimitados. Foi esse reducionismo, esse esforço de abstração no próprio sentido da palavra, que possibilitou a produção de um conhecimento que permitisse uma ação mais decisiva sobre o mundo. Isso quer dizer que o recorte do real pelas disciplinas foi o movimento histórico do pensamento humano que viabilizou o surgimento e o desenvolvimento do pensamento científico.

Esse recorte é arbitrário, não apenas na medida em que segmenta uma totalidade complexa, mas também por ter nascido de um contexto cultural e socioeconômico particular, que era aquele da Europa pós-Renascença, reatando um esforço iniciado na Antigüidade e reafirmando o divórcio que vinha se confirmando, naquela época, entre o ser Humano e o resto do mundo. Quando questionamos o recorte das disciplinas, é preciso, entretanto, não esquecer que a emergência destas e sua possibilidade de pensar o mundo cientificamente surgiram de um mesmo processo histórico. A característica principal do pensamento científico, quando comparado a outras formas de representação do mundo, sejam elas míticas, religiosas ou ideológicas, é a de se apoiar em instrumentos de descrição e de análise dos objetos e dos fatos que transcendem as diferenças entre as culturas e as épocas e possibilitam, ultrapassando o espaço e o tempo, a transmissão e o acúmulo do saber. Ele nunca se confunde com dogma, ficando sempre aberto à crítica, às dúvidas e a aprimoramentos. Por exemplo, ao contrário das cosmogonias míticas ou religiosas que brotaram ao longo da história das culturas humanas, surgindo, desaparecendo e, às vezes, competindo entre si, o papel da Astronomia na descrição e explicação do universo está lastreada em um antigo e contínuo movimento de controvérsias, com base em observações, experimentações e argumentos trocados, até hoje, ao longo dos séculos e das fronteiras espaciais.

No decorrer da história da construção das ciências, o problema maior reside provavelmente na perda da consciência do caráter formal, abstrato e potencialmente provisório desses recortes. Mais do que ângulos de representação do universo, espaços particulares nos quais os poderes da mente humana podem se exercer, o recorte disciplinar, outrora instrumento metodológico para organizar o pensamento, transformou-se em partição de territórios, cada vez mais excludentes um do outro. As fronteiras disciplinares serviram para construir divisões institucionais - principalmente nas universidades - que se transformaram progressivamente em redes de interações privilegiadas, quadros de afirmação de identidade intelectual e, por fim, em territórios de poder. O sistema educacional reforçou e cristalizou o que era no início uma diversidade epistemológica nas abordagens da realidade. Por exemplo, um aluno de Medicina, de Agronomia ou de Engenharia sabe muito pouco ou nada, no final da sua formação, sobre as dimensões sociais dos problemas que vai enfrentar. Por outro lado, é desnecessário falar dos alunos de Ciências Sociais, para os quais o corpo humano ou o universo material simplesmente não existem, a não ser como objeto de modelos e representações sociais. A evolução do mundo acadêmico operou-se, em especial durante o último século, no sentido de uma crescente especialização que tornou cada vez mais difícil a comunicação entre disciplinas. De maneira correspondente, os intercâmbios entre os grupos e os departamentos nas estruturas de ensino e de pesquisa ficaram cada vez mais esparsos ou mesmo inviabilizados.

O paradoxo é que, enquanto se operava esse movimento de especialização, o próprio avanço do conhecimento já sugeria o abandono dos limites disciplinares estabelecidos. Isso aconteceu ao longo de duas direções divergentes:

- pela multiplicação das novas disciplinas - ou subdisciplinas - para estudar novos campos da realidade, outrora concebidos como fora do domínio de alcance da ciência, como por exemplo a genética (que pretende agir no nível das raízes da vida), 
RAYNAUT, C. Meio Ambiente e Desenvolvimento: construindo um novo campo...

a física atômica (que explora e manipula a substância mais íntima da matéria), a astrofísica (que tenta explicar a origem do universo) e as ciências cognitivas (que exploram os processos de emergência da consciência e a estrutura do pensamento);

- por um esforço contrário, para pensar globalmente a complexidade de amplos sistemas que abrangem uma grande variedade de objetos, seres e processos de natureza diferente. Em um nível epistemológico, as obras de Prigogine, Stengers ou de Morin são ilustrativas desse esforço. A perspectiva mais empírica, a "Nova Ecologia", por exemplo, tenta agrupar dentro do conceito de "Panarchy" uma grande diversidade de sistemas de natureza e tamanho diferentes, evoluindo em função de dinâmicas distintas, mas interagindo conforme uma metadinâmica complexa fortemente marcada pela imprevisibilidade.

As disciplinas, entretanto, existem. São os seus conceitos, seus métodos e suas modalidades de validação do conhecimento que constituem, até hoje, a fundamentação de nossa capacidade de conhecer o mundo, bem como de nos conhecermos. Mais do que nunca, neste período de mutação dos quadros de pensamento e de renegociação das fronteiras que definem a posição do ser humano no mundo, pode-se pensar que as barreiras entre as disciplinas e a hiperespecialização científica ocultam o real na sua complexidade e na sua permanente renovação. Pensamos, no entanto, que antes de acabarmos com as fronteiras disciplinares, é preciso, mais modestamente, tentar tornar possível o diálogo e a colaboração entre as disciplinas tal como existem, sem colocar em questão logo de início suas fundamentações teóricas e metodológicas. Isso é perfeitamente compatível com o projeto de fazer com que a colaboração assim estabelecida conduza cada uma delas a uma evolução importante de seus procedimentos e de seus modos de produção do conhecimento.

Nessa perspectiva, chamar pela interdisciplinaridade não significa que todas as pesquisas científicas devam necessariamente ser interdisciplinares. Em outros termos, a interdisciplinaridade não deve se tornar uma nova exigência para toda e qualquer produção científica, mesmo que os modismos que ora afetam as instituições de pesquisa possam às vezes nos fazer pensar o contrário.

São certos objetos e certos assuntos que necessitam de uma colaboração entre diferentes disciplinas para ser adequadamente estudados. De onde surgem e como é que se constroem esses “objetos científicos híbridos"? Sem dúvida, essa construção não pode ser feita a partir da problemática única e interna de uma dada disciplina, uma vez que a coerência de uma problemática disciplinar é dada justamente pela sua capacidade de fixar limites entre o que lhe diz respeito e o que lhe é exterior. No entanto, pesquisadores que se interessam pelas fronteiras de seu próprio campo de atuação podem sentir, como resultado do seu encaminhamento intelectual pessoal, a necessidade de chamar para si a contribuição de outras disciplinas. Isso acontece com freqüência. Muitos são os "conceitos nômades" que circulam entre disciplinas diferentes. Se as ciências sociais falam de "sinergia", de "patamar" e mais recentemente de "resiliência", as ciências naturais utilizam correntemente os conceitos de "população", de "hierarquia", de "conflitos" - até de "revolta". A afirmação da permeabilidade epistemológica dos limites tem conduzido às vezes a um uso descontrolado dessas trocas. Analogias e metáforas passam às vezes por figuras do raciocínio e da administração da prova, alguns pretendendo, por exemplo, aplicar conceitos da física quântica, dos princípios da termodinâmica ou da noção de fluxos de energia à análise dos sistemas sociais. Tais tentativas de intercâmbios e empréstimos, por excessivas que sejam muitas vezes, são testemunhos de um esforço geral de crítica e de refundação dos quadros de pensamento neste período de crise cultural. No entanto, elas raramente fornecem instrumentos utilizáveis para conduzir pesquisas no campo.

Na prática, a identificação inicial de objetos e assuntos de pesquisa interdisciplinar nasce de uma relação com o mundo que não é a mesma da ciência e que não pode se satisfazer em trabalhar com um segmento da realidade isolado por razões apenas conceituais e metodológicas. Tais objetos e assuntos "híbridos" são geralmente reconhecidos a partir de uma posição social, que obriga a considerar a realidade tal como se apresenta na experiência comum, ou seja, como um conjunto de relações que não pode ser reduzido a priori ao recorte instituído pelas disciplinas. Tal posição é, essencialmente, a posição da ação, a partir do momento em que se considera a necessidade dessa ação ser informada por um conhecimento construído. Isso se confirma no caso de muitas operações técnicas que necessitam de vários tipos de conhecimento para serem realizadas. É ainda mais o caso quando se trata de domínios da ação nos quais os problemas técnicos e sociais são estreitamente interligados. Nessas circunstâncias, o esforço de análise é 
confrontado ao mesmo tempo pelas propriedades dos sistemas sociais e dos sistemas físicos e naturais. Esse é o caso, em especial, das questões ligadas ao desenvolvimento e ao meio ambiente.

\section{Desenvolvimento e meio ambiente: a necessidade de estudar as relações sociedade/natureza}

Pensar o desenvolvimento humano, levando em conta suas implicações no domínio do meio ambiente, traz necessariamente consigo a exigência da interdisciplinaridade. A própria noção de meio ambiente é extremamente complexa e ambivalente:

- uma vez que se fala de meio ambiente e não de ecossistemas ou de sistemas físicos ou biológicos, isso implica que a noção integra o ser humano, individualmente ou coletivamente, como ocupante e utilizador de um espaço e do conjunto de objetos e seres bióticos e abióticos que abarca. $\mathrm{O}$ que a palavra meio ambiente designa é o mundo físico e biótico encarado nas suas relações com o homem;

- esta noção é multicêntrica, aplicando-se, conforme as perspectivas adotadas, a indivíduos, grupos, organismos e populações de seres vivos. De uma representação a outra, operam-se deslocamentos de tal maneira que o que era o objeto central da definição torna-se um elemento do meio ambiente em outra. Além disso, os processos abrangidos pela noção de meio ambiente se desenvolvem por meio de múltiplas escalas de espaço e tempo e movimentam uma enorme diversidade de níveis de organização. Da molécula até o ecossistema, do local até a paisagem na sua globalidade, muitos são os níveis de organização a levar em conta na elaboração de um modelo explicativo relativo a uma situação ambiental. $\mathrm{O}$ ritmo das dinâmicas observadas muda segundo as escalas de observação adotadas, passando do instantâneo ao tempo geológico. Isso é evidente quando se tratar dos sistemas físicos e biológicos. Verifica-se também no que diz respeito à vertente humana da relação, segundo o ponto de referência - o indivíduo, a comunidade local, a na- ção, os bilhões de seres humanos povoando a Terra. O significado do termo "meio ambiente" e os fenômenos a serem analisados mudarão, passando das condições de vida que oferece a uma pessoa e ao seu entorno imediato de vida, para chegar ao planeta e às mudanças globais e de longo prazo às quais este é submetido. Não se trata aqui apenas de diferenças formais, já que para cada nível de análise surgem propriedades que não existiam no nível inferior. Uma célula não é meramente a soma de moléculas; uma floresta diferencia-se da justaposição das árvores. Descrever e analisar essa realidade complexa implica a intervenção de várias disciplinas atuando em vários níveis de apreensão e utilizando diversos instrumentos teóricos e conceituais.

No âmbito de uma interrogação estritamente científica, é possível selecionar um número limitado de níveis e ângulos de análise dentro dessa complexidade, em função dos objetivos de conhecimento perseguidos e das competências disponíveis. O domínio de estudo escolhido nessa perspectiva está geralmente focado nas relações entre um número limitado de fatores e algumas características particulares de um ecosistema (por exemplo, entre as variações climáticas e o crescimento das plantas ou entre um certo tipo de intervenção humana e a diversidade biológica de um meio natural). Pouco a pouco, em função dos progressos do conhecimento, novos fatores são encarados, ou novos aspetos da dinâmica dos sistemas físico-naturais, tornando-se assim progressivamente mais complexo o modelo de descrição da realidade. Mas quando se encaram os processos ambientais a partir dos seus desdobramentos mais sensíveis para a existência humana, como, por exemplo, nos casos da desertificação, das chuvas ácidas ou do aquecimento global, não é mais possível impor limites a priori ao campo de estudos. Torna-se imprescindível um esforço de superação das abordagens setoriais limitadas à pesquisa de causalidades lineares e reduzidas a um só nível de apreensão. Por sua própria natureza, os problemas decorrentes do campo ambiental reclamam uma ótica que destaque as inter-relações entre fenômenos, as correspondências entre níveis de organização e a imbricação de ligações causais.

Quando se consideram não apenas as conseqüências de processos ambientais sobre as sociedades humanas, mas também a necessidade de incorporar as dimensões ambientais na formulação das políticas de desenvolvimento - harmonizando-se objetivos econômicos, sanitários, 
RAYNAUT, C. Meio Ambiente e Desenvolvimento: construindo um novo campo...

sociais e éticos com a preservação da natureza - a exigência de interdisciplinaridade faz-se ainda mais presente, abrindo-se para um espaço mais amplo. A colaboração entre ciências físico-naturais, disciplinas técnicas e ciências sociais torna-se absolutamente necessária, uma vez que se trata de analisar não somente a complexidade dos sistemas físico-naturais, mas também aquela, muito maior, das suas interações com as sociedades. Na medida em que, falando de meio ambiente, são colocadas no centro das preocupações as relações entre as sociedades humanas e o meio físico-natural que elas ocupam e exploram, o ser humano não pode mais ser considerado como "hóspede" do meio que habita. Ele apresenta-se necessariamente como parte integrante desse meio, do qual é, ao mesmo tempo, sujeito e objeto, ator e produto.

O meio ambiente, assim concebido, inscreve-se dentro de uma representação ampla, que reúne subsistemas que interagem e mesmo compartilham elementos comuns, embora se organizem segundo propriedades estruturais e funcionais diferentes. Várias noções foram propostas para designar esse conjunto: por exemplo, alguns falam de "Antropossistemas"; outros de "Ecossistemas" humanos. Essa representação sincrética da realidade constitui um avanço do ponto de vista conceitual, na medida em que pretende superar a dicotomia entre o ser humano e o resto do mundo - dicotomia hoje questionada. Mas, do ponto de vista da construção do conhecimento científico, ela pode levantar problemas teóricos e metodológicos importantes. Efetivamente, não se pode analisar a rede de relações de um sistema complexo, - com vários níveis, vários subsistemas - apenas a partir de um modelo de interação generalizada. Trabalhar sobre relações exige que os elementos e os subsistemas inter-relacionados sejam identificados e diferenciados, com suas especificidades claramente ressaltadas.

Definir o quadro referencial das diferenciações a partir das quais as relações vão ser analisadas é a primeira etapa do processo de análise. Por isso, embora se afirme que não existe dicotomia entre o ser Humano e o resto do mundo, permanece válida a necessidade de fundamentar a análise das relações mútuas sobre o reconhecimento inicial do que constitui a diferença entre eles. Desse modo, há a possibilidade de se organizar a coleta de dados empíricos e a construção de modelos teóricos. Operando assim, não se trata de erguer fronteiras estanques, mas sim de identificar campos de observação distintos, para poder analisar como as propriedades estruturais e funcionais de cada um se arti- culam, se combinam ou confrontam as propriedades do outro.

Isso leva à construção de um modelo analítico, no qual se encontram dois "campos" de realidade distintos e, ao mesmo tempo, estreitamente interligados:

- o Campo das relações físicas e biológicas, que compreende o conjunto de relações biológicas e físico-químicas tecidas no bojo dos grandes domínios de organização biológica, como a atmosfera, pedosfera, hidrosfera e geosfera. Essa rede de relações forma um sistema, subdividindo-se em muitos subsistemas imbricados e articulados a várias escalas. Ela inclui o homem - tomado individualmente ou reunido em populações - enquanto considerado na sua dimensão de organismo vivo, agente e objeto de interações biológicas e físico-químicas. Inclui também uma parte fortemente artificializada - a ponto de ser, às vezes, como a cidade, um produto direto da ação humana (um artefato) - mas que não deixa de permanecer submetida a processos da mesma ordem dos meios físicos e biológicos;

- o Campo das relações não-materiais compreende o conjunto de processos cuja articulação participa na organização, na reprodução e na transformação das representações mentais do mundo e dos modos de estruturação das relações sociais. Aqui, os fatos que o olhar científico busca identificar, descrever e compreender remetem a processos de produção, de circulação e de transmissão do sentido tanto no ponto de vista da cultura coletiva (representações, valores, normas) quanto dos intercâmbios entre atores sociais. Esses processos desempenham um papel determinante na história de qualquer sociedade e permanecem, em grande parte, autônomos em relação às determinações biológicas e físico-químicas. Como já apontamos mais acima, idéias têm a capacidade de engendrar outras idéias, relações sociais criam condições (tais como tensões, conflitos, solidariedades, construção de identidades etc.) para a emergência de novas relações sociais. Para construir um conhecimento sobre a organização, o funcionamento e a dinâmica histórica de um sistema social - e isso é o papel das ciências sociais essa dimensão imaterial da realidade é tão objetiva (no sentido de "possuir uma existência intrín- 
seca") e tão explicativa quanto as condições materiais às quais o mesmo sistema acha-se submetido.

Distinguir essas duas vertentes da realidade e afirmar que cada uma se constitui como um objeto específico de conhecimento científico é uma etapa essencial em um esforço de descrição e de compreensão da complexidade do mundo. Mas não basta reafirmar o caráter intrínseco de cada "campo de fatos". Por distintos que sejam, não deixam de ser estreitamente ligados entre si.

Nenhuma sociedade poderia existir sem uma base material, como o próprio corpo dos indivíduos que a compõem, os bens e os objetos cuja produção, circulação e consumo permitem a reprodução social e os apetrechos e interações biofísicas envolvidos na fabricação desses bens e objetos. Essa base material é parte integrante do estudo do sistema das relações não-materiais quando, e unicamente quando, contribui para produzir ou transformar as relações sociais e os quadros de representação. Por exemplo, um evento biológico tal como a epidemia da aids pode exercer uma maior influência sobre as evoluções nas relações de gênero. Outro exemplo, as novas técnicas de transplante de órgãos ou as biotecnologias provocaram mudanças profundas na definição da morte e da vida, suscitando questões éticas outrora nunca enfrentadas. No entanto, por mais importante que possa se revelar a influência de fatos materiais sobre a dinâmica das idéias, eles nunca a determinam diretamente. Os fatos materiais são sempre interpretados em função de categorias de pensamento - e/ou relações de poder - já preexistentes e que fornecem o quadro a partir do qual novos ajustes terão de ser feitos. Por exemplo, as novas definições da vida e da morte, do humano e do nãohumano, hoje em andamento, não são simples adaptações aos progressos recentes da biologia, da genética e da medicina, mas sim reelaborações das definições herdadas da nossa história social e cultural - reelaborações que integram as novas perspectivas abertas pelas técnicas modernas, mas que fundamentalmente respondem a mudanças radicais nas exigências dos indivíduos no que diz respeito à sua saúde, ao seu desejo de ter filhos, à satisfação da suas aspirações de ser felizes. Diferentes medidas legais foram adotadas por diversos países para regimentar práticas técnicas de clonagem ou manipulações genéticas. Isso é uma ilustração do papel das dimensões culturais e políticas na interpretação das mesmas inovações científicas e técnicas.

No entanto, muitas realidades materiais não podem ser analisadas desconsiderando-se que são o resultado da ação dos seres humanos, ou seja, dos seus saberes, projetos, desejos, sonhos e fantasmas, bem como das suas formas de organização coletiva. Por exemplo, uma paisagem, no sentido que os geógrafos dão à palavra, embora seja constituída de nada mais do que solos, plantas, rios, planícies, montes - elementos interligados por relações físicas e bioquímicas - constitui-se também, de modo fundamental, como o produto de uma sociedade humana e de sua história. A questão ambiental, por si mesma, é a manifestação da tomada de consciência da capacidade do ser humano para modificar a natureza, às vezes danificando e destruindo, mas também manejando e moldando até dar nascimento a uma "Segunda Natureza", como já foram qualificados desde a Antigüidade os espaços transformados pelas atividades humanas. A visão de uma natureza virgem e intocada não passa de um mito e quase todos os meios "naturais" no mundo não podem ser analisados sem levar em conta o papel da intervenção humana na sua dinâmica. As evoluções do saber científico e das técnicas durante os dois séculos passados fazem com que a capacidade de intervenção do ser humano tenha sido amplificada e estendida, abrangendo todos os níveis de organização da matéria inerte ou viva, desde o átomo até o planeta inteiro.

Todas essas colocações não passam de banalidades, muitas vezes repetidas. Mas às vezes pode ser útil relembrar algumas banalidades quando elas ajudam a clarificar um problema e a maneira de abordá-lo. Conforme a perspectiva que acabei de resumir, tratar de uma questão relativa ao meio ambiente implica a análise das relações tecidas dentro do macrosistema, que compreende os seres humanos e o meio biótico e abiótico. Mas uma vez afirmada a necessidade desse enfoque globalizante (holístico), devemos ir além, afirmando que esse enfoque só pode ser aplicado no quadro de uma diferenciação entre os dois domínios distintos - as duas lógicas - de relações (materiais e não-materiais) que acabei de apresentar. Isso não quer dizer que os dois domínios devem ser estudados de modo separado recriando a dicotomia entre o homem e o resto do mundo -, mas sim que se deve utilizar o fato de distingui-los como um procedimento heurístico para analisar sua interface e suas interações.

Quando se fala de meio ambiente, sempre se trata do que está acontecendo nessa interface, combinando as duas lógicas e os dois campos de interação. A conseqüência imediata dessa constatação é que trabalhar as questões ambientais exige a participação simultânea das ciências sociais e das ciências naturais. A condição básica do êxito 
RAYNAUT, C. Meio Ambiente e Desenvolvimento: construindo um novo campo...

da colaboração entre as mesmas reside no reconhecimento, por cada grupo de disciplinas, da pertinência, para responder a seu próprio questionamento, do que está acontecendo no domínio da realidade explorado pelo outro grupo:

- as ciências sociais devem reconhecer a natureza profundamente ambivalente da pessoa humana e das sociedades - sua dupla natureza - ao mesmo tempo essencialmente "ideacional" ou imaterial e profundamente arraigada na matéria, o que Godelier chama de "a parte não social do social".

- por outro lado, as ciências físicas e naturais devem admitir que as produções da mente humana - representações, símbolos, valores, saberes - não são meras fantasias, que vêm enfeitar ou mascarar uma realidade mais essencial e mais determinante que seria a realidade da matéria. Devem aceitar que a dimensão social, cultural, faz parte integrante da realidade e desempenha um papel determinante tanto na história das sociedades quanto naquela dos ecossistemas que estudam.

Para atingir a colaboração no estudo de problemas ambientais, as disciplinas sociais e naturais devem conciliar duas exigências:

- produzir um conhecimento voltado para objetos coerentes com seus conceitos e seus métodos. Em outras palavras, um antropólogo não vai estudar a dinâmica dos ecossistemas e um ecólogo não vai analisar a elaboração das representações;

- reconhecer o caráter fundamentalmente ambivalente dos fatos sobre os quais elas trabalham - ao mesmo tempo materiais e sociais - o que torna igualmente pertinentes os diversos saberes produzidos sobre um mesmo objeto.

\section{O desenvolvimento sustentável: as ambigüidades da noção}

É claro que esse esforço para esclarecer a forma de pensarmos as relações entre o homem e seu ambiente tem desdobramentos na noção de desenvolvimento. No decorrer da história do século 20, essa noção tem sido fortemen- te ligada àquelas de progresso e de modernidade. Foi-lhe dado uma dimensão meramente quantitativa - tratava-se de produzir mais bens e mais serviços, ora para cumprir necessidades básicas definidas dentro de uma economia planificada, ora para alimentar um mercado que supostamente levaria, por seus próprios ajustes internos, ao mesmo resultado. Por desigual que fosse o processo, que cavou um abismo entre os mais ricos e os mais pobres, isso resultou efetivamente em uma progressão muito rápida das produções ao nível mundial. As conseqüências dessa visão do desenvolvimento são bem conhecidas e discutidas. Ela resultou em situações de miséria física e social profunda para as populações que não se beneficiaram dos seus ganhos. Gerou também conflitos nas relações sociais e confusões de sentido nas camadas socioeconômicas privilegiadas e nos países ricos. Do lado ambiental, os danos são enormes, tanto em níveis locais e regionais quanto no nível global do planeta.

Muitas críticas foram formuladas sobre esse modelo de desenvolvimento que privilegia as dimensões técnicas e econômicas do funcionamento das sociedades humanas, ignorando os aspectos sociais e culturais (não-materiais). É um modelo que desconsidera os efeitos, imediatos ou de longo prazo, do "progresso" sobre o meio ambiente. A noção de "desenvolvimento sustentável" representa um esforço para conceber um outro modelo de desenvolvimento, que integre dimensões que estavam, até então, deixadas de fora. A noção combina preocupações ligadas às relações sociais - integrando os objetivos de justiça e de eqüidade - e preocupações voltadas para a preservação ou a recuperação do equilíbrio dos meios "naturais". Esta noção teve sucesso jamais obtido por outras anteriores, como a de "desenvolvimento humano" ou para a de "eco-desenvolvimento". Consta doravante da agenda do Banco Mundial, do FMI e de muitas políticas nacionais, bem como de movimentos ambientalistas e movimentos sociais.

Tal sucesso não pode ocorrer sem muita ambigüidade e muitas interpretações contraditórias. Para alguns, "desenvolvimento sustentável" significa achar os meios técnicos para continuar produzir ao mesmo ritmo mas reduzindo os danos ambientais. Outros, quando utilizam a mesma noção, colocam como prioridade a proteção ambiental e a sustentabilidade da "natureza" a curto e longo prazo. Outros, por fim, privilegiam a "sustentabilidade social", buscando reduzir a pobreza, considerada como principal fonte de desequilíbrio nos sistemas sociais e causa de danos aos meios "naturais". Essas diferenças de perspectivas se cru- 
zam com outras diferenças, ligadas à escala espacial e temporal adotada para colocar a questão da sustentabilidade.

A noção de "desenvolvimento sustentável" é relativa. Ela varia em função de quem a utiliza e de onde ele se situa - no tempo e no espaço - para definir seu conteúdo. A sustentabilidade para uma comunidade local à procura dos meios da sua reprodução física e social no seu ambiente de vida não vai ter o mesma significado para um movimento ambientalista que pretende preservar a "Mata Atlântica", elemento do patrimônio mundial ou para uma empresa que busca "externalizar" os danos ambientais que causa no seu entorno, exportando os resíduos para zonas longínquas. Quando se fala de sustentabilidade, devemos sempre nos perguntar: "sustentabilidade para quem?'

No entanto, além da diversidade das interpretações, das prioridades e dos objetivos dos atores sociais, uma mesma aspiração reúne esses vários pontos de vista, que é a busca de um novo "equilíbrio" nos sistemas naturais, nos sistemas sociais e nas relações entre os dois. A questão das relações entre os seres humanos, as sociedades e o mundo biofísico é central para essa problemática, mas permanece colocada a partir de mitos (mito da Natureza, mito do Progresso, mito da Técnica) e de pré-noções frouxas e mal elaboradas (de Equilíbrio, de Harmonia).

Apoiando-se a perspectiva complexa e dinâmica das relações sociedades/natureza - como acabei de esboçar - e em um enfoque interdisciplinar dos problemas de desenvolvimento e de meio ambiente, a pesquisa científica pode, se não trazer respostas definitivas, aos menos ajudar a esclarecer as questões colocadas e produzir um saber complexo e com nuances, utilizável em uma negociação social, necessariamente conflitante, entre atores portadores de definições diferentes do desenvolvimento e da sustentabilidade. A reflexão crítica sobre a noção de "desenvolvimento sustentável", conduzida a partir de realidades concretas e não em função de posições axiomáticas, é uma das tarefas principais da pesquisa interdisciplinar sobre as relações Sociedades/Meio Ambiente.

\section{Conclusão - A interdisciplinaridade é uma prática a ser construída}

Passar de um quadro conceitual geral para uma prática concreta de pesquisa interdisciplinar não deixa de constituir um desafio metodológico. A interdisciplinaridade não é decretada, ela se constrói. Não é por termos identificado um problema cujo tratamento parece exigir a contribuição de várias disciplinas que este se constitui automaticamente em um tema de pesquisa científica. O problema não é em si uma razão suficiente para que essas disciplinas se disponham espontaneamente a colaborar. Todo um trabalho de reconstrução é necessário para passar da problemática de ação à problemática científica e para identificar as questões específicas que possam ser respondidas pelas diversas disciplinas com suas próprias competências. É preciso, também, organizar a pesquisa, definindo a maneira como vão se articular os diferentes trabalhos dos especialistas, o quadro referencial comum (em termos de amostragens, de escala de análise, de temporalidade), graças aos quais poderão se reunir e confrontar os resultados que cada um obteve dentro de seu campo e com seus métodos específicos. É desejável, e habitualmente possível, que ao menos uma operação comum reúna os diferentes pesquisadores em torno de um trabalho de coleta e análise de dados. São esses procedimentos metodológicos que vamos ter a oportunidade de discutir, a partir de casos concretos, durante este seminário. Com certeza, vamos encontrar todas as dificuldades, todos os obstáculos, que se erguem no longo desse caminho.

Para quem quer ir além das declarações de princípios, a prática interdisciplinar permanece um desafio ainda não superado. Neste período de dúvidas, de renegociação de fronteiras e de conceitos, muitos são os pesquisadores que tentam se apropriar de achados, noções e métodos oriundos de disciplinas diferentes da sua. Esses intercâmbios podem ser proveitosos - eles constam do movimento de remodelagem dos campos disciplinares - e podem abrir novas perspectivas. É claro, por exemplo, que a "Nova Ecologia", com sua visão dinâmica e histórica dos ecossistemas, oferece muitos elementos de reflexão às ciências sociais e lhes abre interessantes perspectivas para aprofundar o conceito de "reprodução" associado àquele da tensão permanente, em todo processo histórico, entre "permanência" e "mudança". No entanto, esses intercâmbios tornam-se perigosos quando levam à tentação da prática de uma interdisciplinaridade solitária ou de construir às pressas uma transdisciplinaridade que corre o risco de não passar de ser um patchwork de idéias discordantes e mal costuradas.

A interdisciplinaridade é sempre um processo de diálogo entre disciplinas firmemente estabelecidas na sua identidade teórica e metodológica, mas conscientes de seus limites e do caráter parcial do recorte da realidade sobre a 
RAYNAUT, C. Meio Ambiente e Desenvolvimento: construindo um novo campo...

qual operam. Isso implica, por parte dos pesquisadores, respeitar o saber produzido por outras disciplinas e recusar qualquer hierarquia a priori entre elas, relativa ao poder explicativo dos fatos sobre os quais elas trabalham. Implica também, fundamentalmente, o desejo de aprender dos outros e a ausência de toda postura defensiva de um território de poder simbólico ou institucional. Sem dúvida, é aqui que se acham os obstáculos mais evidentes para a colaboração interdisciplinar. 